\title{
BRAZILIAN FREE-TAILED BATS AS INSECT PEST REGULATORS IN TRANSGENIC AND CONVENTIONAL COTTON CROPS
}

\author{
Paula Federico, ${ }^{1}$ Thomas G. Hallam, ${ }^{1,11}$ Gary F. McCracken, ${ }^{1}$ S. Thomas Purucker, ${ }^{1,12}$ William E. Grant, ${ }^{2}$ \\ A. Nelly Correa-Sandoval, ${ }^{3}$ John K. Westbrook, ${ }^{4}$ Rodrigo A. Medellín, ${ }^{5}$ Cutler J. Cleveland, ${ }^{6}$ \\ Chris G. Sansone, ${ }^{7}$ Juan D. López, Jr., ${ }^{4}$ Margrit Betke, ${ }^{8}$ Arnulfo Moreno-Valdez, ${ }^{9}$ and Thomas H. Kunz ${ }^{10}$ \\ ${ }^{1}$ Department of Ecology and Evolutionary Biology, 569 Dabney Hall, University of Tennessee, Knoxville, Tennessee 37996 USA \\ ${ }^{2}$ Ecological Systems Laboratory, Department of Wildlife and Fisheries Sciences, Texas A\&M University, \\ College Station, Texas 77843-2258 USA \\ ${ }^{3}$ Centro de Calidad Ambiental, Tecnológico de Monterrey, Monterrey, Neuvo Leon, Mexico \\ ${ }^{4}$ USDA-ARS, Areawide Pest Management Research Unit, 2771 F\&B Road, College Station, Texas 77845-4966 USA \\ ${ }^{5}$ Instituto de Ecología, Universidad Nacional Autónoma de México, Ap. Postal 70-275, 04510 Ciudad Universitaria, D.F., Mexico \\ ${ }^{6}$ Center for Energy and Environmental Studies and Department of Geography and Environment, Boston University, \\ 675 Commonwealth Avenue, Boston, Massachusetts 02215 USA \\ ${ }^{7}$ Texas A\&M University Research and Extension Center, 7887 U.S. Highway 87 North, San Angelo, Texas 76901 USA \\ ${ }^{8}$ Department of Computer Science, Boston University, Boston, Massachusetts 02215 USA \\ ${ }^{9}$ Instituto Tecnológico de Cd. Victoria, Bulevard Emilio Portes Gil \#1301, Cd. Victoria, Tamaulipas, C.P. 87010 Mexico \\ ${ }^{10}$ Center for Ecology and Conservation Biology, Department of Biology, Boston University, Boston, Massachusetts 02215 USA
}

Abstract. During the past 12000 years agricultural systems have transitioned from natural habitats to conventional agricultural regions and recently to large areas of genetically engineered (GE) croplands. This GE revolution occurred for cotton in a span of slightly more than a decade during which a switch occurred in major cotton production areas from growing $100 \%$ conventional cotton to an environment in which 95\% transgenics are grown. Ecological interactions between GE targeted insects and other insectivorous insects have been investigated. However, the relationships between ecological functions (such as herbivory and ecosystem transport) and agronomic benefits of avian or mammalian insectivores in the transgenic environment generally remain unclear, although the importance of some agricultural pest management services provided by insectivorous species such as the Brazilian free-tailed bat, Tadarida brasiliensis, have been recognized.

We developed a dynamic model to predict regional-scale ecological functions in agricultural food webs by using the indicators of insect pest herbivory measured by cotton boll damage and insect emigration from cotton. In the south-central Texas Winter Garden agricultural region we find that the process of insectivory by bats has a considerable impact on both the ecology and valuation of harvest in Bacillus thuringiensis (Bt) transgenic and nontransgenic cotton crops. Predation on agricultural pests by insectivorous bats may enhance the economic value of agricultural systems by reducing the frequency of required spraying and delaying the ultimate need for new pesticides. In the Winter Garden region, the presence of large numbers of insectivorous bats yields a regional summer dispersion of adult pest insects from $B t$ cotton that is considerably reduced from the moth emigration when bats are absent in either transgenic or non-transgenic crops. This regional decrease of pest numbers impacts insect herbivory on a transcontinental scale. With a few exceptions, we find that the agronomics of both $B t$ and conventional cotton production is more profitable when large numbers of insectivorous bats are present.

Key words: Bacillus thuringiensis; Brazilian free-tailed bats; corn; corn earworm; cotton; cotton bollworm; Helicoverpa zea; insectivory; mathematical model; Tadarida brasiliensis; Texas Winter Garden agricultural region, USA; transgenic agricultural crops.

Manuscript received 4 April 2007; revised 28 August 2007; accepted 12 October 2007; final version received 20 November 2007. Corresponding Editor: J. A. Powell.

${ }^{11}$ Corresponding author: E-mail: thallam@utk.edu

12 Present address: Ecosystems Research Division, National Exposure Research Laboratory, Office of Research and Development, U.S. Environmental Protection Agency, 960 College Station Road, Athens, Georgia 30605 USA.

\section{INTRODUCTION}

To improve and sustain agricultural production, biotechnology scientists have developed a suite of genetically modified crops to address a spectrum of biological, chemical, and physical stressors. The agricultural benefits of genetically engineered (GE) products include improved pest management and disease resistance, enhanced chemical benefits from herbicide tolerance and decreased pesticide usage, and decreased impact of physical environmental stressors such as 
temperature, drought, or salinity. The United States quickly adopted agricultural biotechnology and in 2005 remained the world leader in planting of GE crops $(55 \%$, 49.8 million of the 90 million hectares; James 2006).

Primary foci of agronomics of GE crops have been farm profit and subsidies. Antipodal concerns expressed about GE crops have largely concentrated on areas of food safety and health risks. Public apprehension about transgenic crops and organisms exists often because sublethal or direct and indirect effects in ecosystems are not well understood. Recent evidence from the Winter Garden region of south-central Texas, USA, an agricultural area that produces significant quantities of GE crops, indicates that Brazilian free-tailed bat (Tadarida brasiliensis) populations, which are voracious predators of GE herbivores, are declining (McCracken 2003), and at present no documentation for this decline exists.

Genetic engineering, which revolutionized agriculture, also transformed the ecology and evolutionary biology of agricultural systems. The remaining four subsections of this Introduction cover some ecological and evolutionary aspects of transgenic cotton, insectivory, and the Winter Garden agro-food webs, as preliminaries for development of our mathematical model. In Transgenic cotton, important characteristics of genetically engineered cotton, such as effects in agroecosystems, are discussed. From an agronomic perspective, pest control is necessary for successful crop production. In Insectivory, we discuss the important role of natural biological control in agricultural systems. Our Winter Garden study area supports a special agricultural food web that includes transgenic cotton, pest insects, and a top insectivore. In Winter Garden agro-food webs, we present some physical attributes of the Winter Garden region and delineate the biological components of the generic food web.

\section{Transgenic cotton}

The commercialization of genetically engineered cotton has followed the path of an extremely rapid adoption of agricultural biotechnology enhancements (Williams 2006). Plant-incorporated protectant (PIP) cotton strains that express genes of the soil bacterium Bacillus thuringiensis (Bt), such as the cultivars BollGard (Monsanto, St. Louis, Missouri, USA) and Widestrike (Dow Agrosciences, Indianapolis, Indiana, USA), are among the most common varieties of transgenic cotton. In the Winter Garden region, B. thuringiensis-enhanced crops comprised only $25 \%$ of the cotton acreage in the late $1990 \mathrm{~s}$, whereas $B$. thuringiensis varieties accounted for $\sim 95 \%$ of the cotton planted in the 2005 growing season. Databases available from the USDA National Agricultural Statistics Service indicate that the conversion from conventional cotton to PIP cotton varieties is not simply a Texas regional trend. Many large cottonproducing states, including Georgia, Mississippi, and North Carolina, deployed GE cotton crops in 2005 at the rate of 95-96\% for all cotton acreages (USDA AMS, Cotton Program 2005, information available online). ${ }^{13}$

The economics of $B$. thuringiensis transgenic cotton production has been addressed from an individual farm perspective (e.g., Armstrong et al. 2003); however, ecological impacts of the switch to GE cotton generally have not been solidified for agricultural or for natural ecosystems. For example, food chain effects, especially those in which a component of the food chain is an avian or a mammalian species, remain unclear.

The PIP varieties that express $B$. thuringiensis genes yield crystalline proteins that are toxic to nonresistant, targeted insects and, at times, can affect some nontargeted pest species (Marvier et al. 2007). These microbial toxins are specific disruptors of insect midgut membranes (IRAC 2005), but this mode of action requires the presence of midgut bacteria for insecticidal activity (Broderick et al. 2006). Federally approved $\mathrm{Bt}$ cotton plants currently contain up to four modified forms of the Cryptochrome (Cry) gene from $B$. thuringiensis and are used extensively to control lepidopteran pests, particularly the larvae of the cotton bollworm (also known as the corn earworm), Helicoverpa zea (Boddie). Variation exists in levels of expression of the toxins in different varieties of commercial Bt cotton (Adamczyk and Gore 2004) and in different parts of the transgenic plant (Adamczyk and Sumerford 2001). Supplemental insecticide applications are often necessary to control insects in Bt cotton (Burd et al. 1999). When $B t$ technology is supplemented with insecticide applications, $>95 \%$ of the targeted pests may be killed (Johnson et al. 2002).

\section{Insectivory}

Insectivory is a vital agro-ecological service in which consumption removes insects (van Lenteren 1993, Groot and Dicke 2002, Mols et al. 2005, Cleveland et al. 2006). Broad-spectrum insecticides that affect multiple insectivorous species as well as $B t$ pesticides can result in direct effects on pest consumers. The impacts of insecticides also can affect ecological processes and evolutionary constraints in agroecosystems in direct and indirect ways. Insects that survive spray insecticide application or systemic toxins are either fortunate in avoiding the insecticide or are those that are resistant and can genetically pass on this tolerance or resistance to their offspring. Insectivore harvesting of chemically stressed survivors may retard the evolution of insecticide resistance by reducing numbers of homozygous or heterozygous resistant insects. Consumption of resistant insects by natural enemies enhances the agronomics of agricultural systems by diminishing the frequency and concentration of insecticide-active spray ingredients. This process could delay the ultimate need for new insecticides. In this way, the presence of chemical

\footnotetext{
${ }^{13}$ /www.cottoninc.com/CropQualitySummary/>
} 


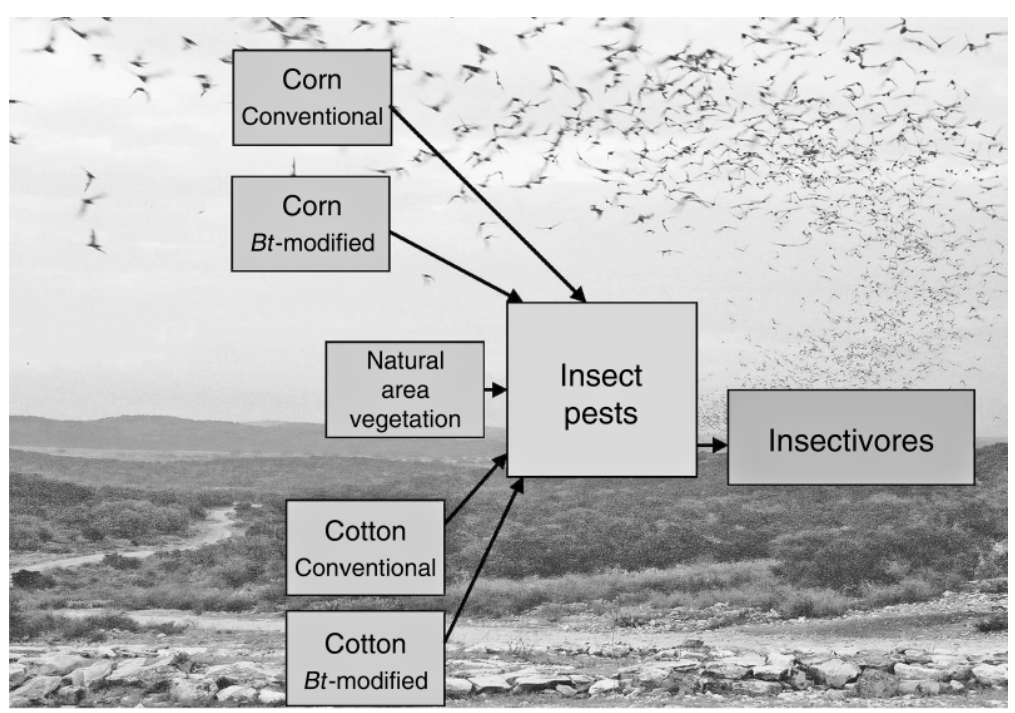

FIG. 1. The conceptual model of the Winter Garden, Texas, USA, agroecosystem. Generic components include insect habitat, insect pest species, and insectivores (here, Brazilian free-tailed bats [Tadarida brasiliensis]). Insect habitat is natural environments and conventional or transgenic crops. See Introduction: Winter Garden agro-food webs for major agricultural pests. We utilize the cotton bollworm (Helicoverpa zea) as the major pest for determination of model parameters.

control in an agroecosystem may enhance the ecological importance of natural predators by investing them with altered ecological and evolutionary traits. In contrast, the food web agroecology of insectivorous species can be indirectly impacted by insecticidal applications. For example, effects of PIP crops have been suggested as the cause for loss of insect predators (e.g., golden-eyed green lacewing insects [Chrysoperla oculata Say]) that prey on the European corn borer, Ostrinia nubilalis (Hübner), a pest targeted by $B t$ corn (Hilbeck et al. 1998, Romeis et al. 2006). If the efficacy of $B t$ cotton toxins is sufficiently high, then loss of insectivores that rely on targeted insect pests to support energetic requirements could have adverse effects. From an ecological perspective, the effects could include changes in biodiversity (Romeis et al. 2006). Agriculture could also suffer with diminished pest control services resulting from insectivores that have switched to alternate prey or decreased foraging in the production area.

\section{Winter Garden agro-food webs}

The Texas Winter Garden region has an average rainfall of $590 \mathrm{~mm}$ annually. Temperatures range from an average low of $2.8^{\circ} \mathrm{C}$ and average high of $17.2^{\circ} \mathrm{C}$ in January to an average low of $21.7^{\circ} \mathrm{C}$ and average high of $36.7^{\circ} \mathrm{C}$ in July. The Winter Garden area is distinctive in that during the warm spring and hot summer months it has a migrant population of Brazilian free-tailed bats (Tadarida brasiliensis) estimated to be in the order of millions (McCracken 2003). These aerial insectivores provide a robust pest management service (Cleveland et al. 2006) and represent an important component in an agricultural food web consisting of non-transgenic and $B t$ corn, non-transgenic and $B t$ cotton, other GE crops, plants in natural areas, and numerous species of pest insects (Fig. 1).

The Brazilian free-tailed bat population in southcentral Texas during the summer consists primarily of adult females that form maternity colonies (McCracken 2003), although some colonies may include a substantial number of males (Keeley and Keeley 2004). Each lactating female during peak lactation consumes approximately two-thirds of her body mass in insects per night (Kunz et al. 1995, Lee and McCracken 2002), and moths can constitute $\sim 30 \%$ of a bat's diet (Kunz et al. 1995, Whitaker et al. 1996, Lee and McCracken 2002, 2005). Helicoverpa zea represents a large percentage of the diet of Brazilian free-tailed bats, especially during the lactation period (Lee and McCracken 2002, 2005; G. F. McCracken and J. K. Westbrook, personal observation). Other relevant lepidopteran pest species in this food web include fall armyworms (Spodoptera frugiperda, J. E. Smith), beet armyworms (Spodoptera exigua (Hübner)), cabbage loopers (Trichoplusia ni (Hübner)), and tobacco budworms (Heliothis virescens, F.). The abundance of these agricultural pests is a function of weather conditions and time of the growing season (J. K. Westbrook, personal observation).

The adult population of $H$. zea present in the area during the growing season comes from local sources and via immigration. Wild hosts in non-cultivated or natural areas in the Winter Garden region initially serve as an adult source. Local populations are regularly augmented by immigrants arriving from more southerly cropgrowing regions in southern Texas and Mexico (Westbrook et al. 1995, Wolf et al. 1995). The major influx of adult bollworms into cotton consists of previousgeneration moths produced in corn usually in late June 


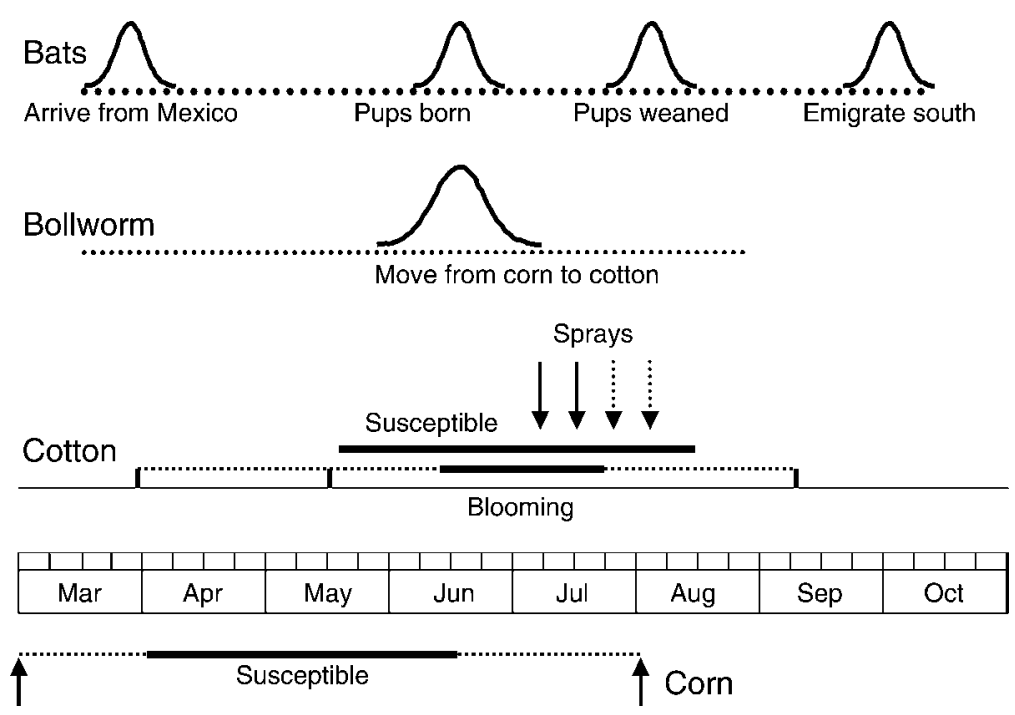

FIG. 2. Approximate timing of the agricultural and the ecological processes in the Winter Garden agroecosystem. A single growing season in the Winter Garden region is our study time frame. Insects and bats migrate from Mexico during March. Pups are born in mid-June, near the time when Helicoverpa zea moths are moving from corn to cotton. The bollworm emergence includes both overwintering and immigrating insects. Pups are weaned in mid-August at approximately the time of emigration of the insects to crops farther north. The final time of insect emigration, approximately the end of August, completes our study time frame. The insecticide sprays are required for conventional cotton.

and cotton in late July and August. The moths fly over the cotton fields, an area spanning $\sim 8000$ ha in 2005 , where they are subject to predation by bats. After mating, these moths oviposit, apparently indiscriminately, on $B t$ and conventional cotton plants (Jackson et al. 2003). When exposed at the larval stages to plantproduced $B t$ toxins, $H$. zea larva have a lower survival rate from egg to the adult (moth) than that of larva present in non-transgenic cotton.

The temporal distribution of $H$. zea and other pest insects in corn and cotton crops is variable due to discrete generations of $\sim 30 \mathrm{~d}$ (J. K. Westbrook, personal observation), but at times this lepidopteron is a dominant agricultural pest of corn, which serves as an insect nursery crop, and cotton, which is infested when the adults emerge from maturing corn. Bollworm larvae also feed on all growth stages of cotton bolls, but as the boll matures, susceptibility to larval penetration is reduced. Growth stages of cotton are important from an agronomic perspective because the bolls set during first three weeks of fruiting are usually the largest, contain the highest fiber quality, and are the primary contributors to crop yield.

The approximate timing of life-history events pertinent to the agro-ecosystem is presented in Fig. 2. The stage dates are flexible and highly dependent on weather conditions. Our model study time frame is a single growing season in the Winter Garden region and begins with the arrival of the first bats. Pups are born in midJune, near the time when $H$. zea moths are moving from corn to cotton. During this time the female bat requires considerable food to produce milk for the pup as well as to maintain itself. Pups are weaned in mid-August at approximately the initial time of the emigration of the insects to crops farther north. The time of insect emigration from the Winter Garden is the end time in our study time frame.

\section{Objectives}

The goal of this study is to help determine the ecological and agronomic roles of insectivory in transgenic cotton agroecosystems. Here, a main feature is development and analysis of a model of an agricultural food chain composed of cotton, bollworms, and Brazilian free-tailed bats over the time frame of a single growing season. For the Winter Garden region, specific objectives are to: (1) identify an ecological indicator that represents a cumulative impact of insectivory by Brazilian free-tailed bats on the agricultural food chain consisting of $B t$ cotton and $H$. zea over a single growing season; (2) delineate the impacts of herbivory in agroecosystems containing transgenic crops in the presence and in the absence of bats; and (3) determine the agronomics of bat insectivory in $B t$ cotton over a single growing season. As a final illustration, we compare some modeling conclusions to those derived from a field data set obtained in North Carolina (Jackson et al. 2003). The details of these data are sufficient to provide information about productivity and insect emigration and to check for relative consistency of the model parameters and outputs in both $B t$ and conventional cotton.

\section{Methods}

Here we formulate the stochastic stage-structured mathematical model of a Winter Garden agricultural food chain. The ecological structures of the food chain 
components (cotton, H. zea, and Brazilian free-tailed bat) and the interactions (herbivory and insectivory) between components are presented as mathematical model representations. Appropriate parameter values in our model are at the physiological level. We indicate how these physiological parameter values and initial conditions are employed in our stochastic model. Next, we indicate numerical techniques used to solve the resulting simulation model. Finally, we describe an agricultural setting in North Carolina, where field study parameters are given at the ecological level of our results. This provides an interesting methodology to test our model results.

\section{The agricultural food chain model structure}

The conceptual model presented in Fig. 3a presents the food chain components as Brazilian free-tailed bats, bollworms, and conventional cotton. The population model for the Brazilian free-tailed bat was structured by sex, with the female subpopulation further stratified by reproductive status (non-pregnant, pregnant, and lactating stages). The largest class of female bats was those that were pregnant. This is consistent with our cave and bridge surveys (T. H. Kunz, personal observation) in which large proportions ( $\sim 90 \%$; Davis et al. 1962) of the females were found to be pregnant after migration to Texas during early spring months. The bollworm population was comprised of both overwintering and immigrant populations and was represented in the stages of egg, larva, pupa, and adult. The cotton plant population was structured by boll location in the lower, middle, or upper thirds of the plant. To account for the differential toxic stress that occurs in Bt crops but not in conventional crops, the larval stage was modified (see Fig. $3 b$ ) for the $B t$ model to represent the dynamics of toxic resistance and larval survival.

\section{The mathematical model}

A stochastic stage-structured model was formulated to investigate the ecology and economic value of bats to non-transgenic cotton production in the Winter Garden region. A difference equation model represents the conceptual model shown in Fig. 3a. To account for the toxicity of $B t$ crops in the ecosystem, the model was modified by dividing the larval stage in the insect component into the stages of exposed larvae and resistant larvae as shown in Fig. 3b. This modification requires two additional parameters representing the "days of exposure" on a $B t$ plant and a supplementary mortality rate resulting from $B t$ exposure.

Indications of some of the difference equations for both conventional and $B t$ cotton are given in Appendix A. Because the two models are the same except for two functions, we will refer to them as a single model because this model can be set to simulate either conventional cotton or $B t$ cotton scenarios by the appropriate choice of parameters. The model was initially formulated as a set of difference equations. A stochastic version was then generated by randomly assigning values from biologically reasonable ranges to a number of sensitive parameters in the equations (see Table 1 for the parameters used). This stochastic model was used in our analysis.

The processes of immigration, birth, and emigration of the bats are represented as temporal distributions in our model that occur over windows of time centered at a peak day. The emergence and dispersal of insects from corn to cotton is represented with temporal normal distributions. This means that, given a total number of insects that will disperse from corn, the proportion moving to cotton on a particular day $t$ is given by probability of dispersing between time $t$ and $t+1$. The probability density function corresponds to a normal distribution with mean equal to the peak day of dispersal. Insecticide sprays are represented as discrete events with a toxic impact that decreases over a period of three days in the simulations.

The model used a total of 43 parameters and initial conditions to represent the food chain ecology and the agricultural processes in the conventional cotton model and 45 parameters in the $B t$ food web. Each parameter, along with its variance, was estimated for the Winter Garden area from literature values (e.g., Sansone and Smith 2001, Sansone et al. 2002, Cleveland et al. 2006), from our field research, or was suggested by local crop experts in the Winter Garden region. There are 12 parameters (and two initial conditions) used in the bat population component, nine of which are obtained from the literature. There are 21 parameters (and one initial condition) used in the insect population component, nine parameters were documented in the literature, and eight parameters were used in the cotton component (and one initial condition) with two parameter values found in the literature. Many of the undocumented parameters involve timing of events such as migration, crop planting time, and other similar quantities, which can vary from year to year depending upon weather conditions. Details are provided in Appendix B, Table B1. Initial estimates of insect densities (19903 adults/ha, $50 \%$ females) have been obtained from emergence and pheromone traps (J. K. Westbrook, unpublished data). Initial values for the bats are assumed to be 863500 immigrants, of which 758000 are females and the remainder males. Of the arriving females, 682200 are assumed to be pregnant upon arrival or immediately thereafter. This corresponds to our conservative estimates of Brazilian free-tailed bat numbers in caves, particularly Frio Cave, and bridges located in the region. The monetary values used as input parameters include a cost of US\$25 per spray and a cotton income of US $\$ 1.10 / \mathrm{kg}$ of cotton lint, with $\sim 770$ bolls $/ \mathrm{kg}$.

The simulation model was solved numerically, and simulation experiments to relate the model with the objectives were formulated. We used the software program STELLA (Isee Systems, Lebanon, New Hampshire, USA) to solve the model. We checked the 

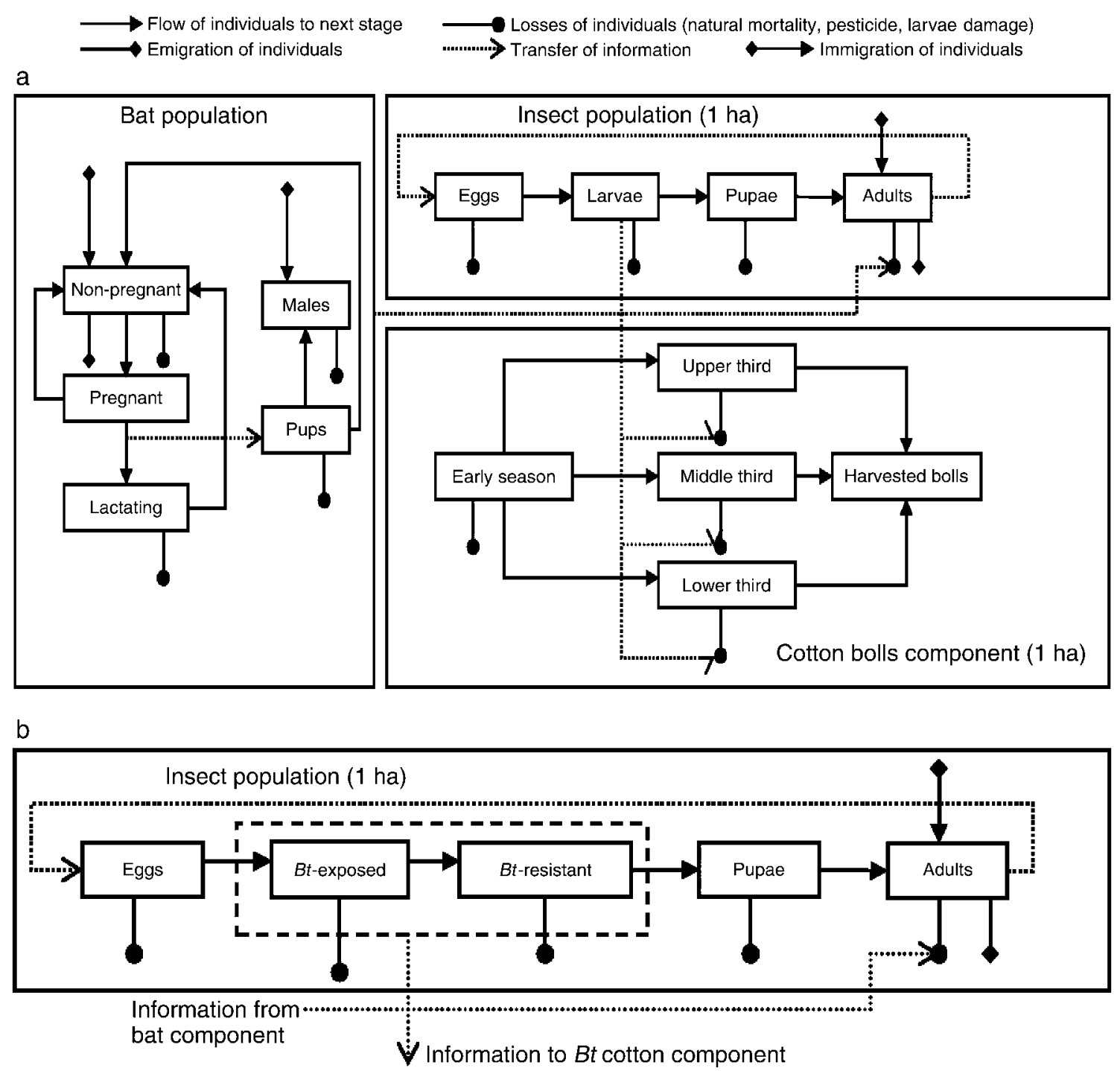

FIG. 3. (a) The structured components of the non-transgenic cotton model for the Winter Garden agroecosystem. The figure depicts structure of the cotton in terms of bolls, insects in terms of stages, and bats in terms of males, females, and pups with an additional substructure for females in terms of reproductive phase. The arrowheads describe the character of the flows indicating transport of individuals from class to class or into class by immigration, losses due to mortality or emigration, and information transfer. (b) The additional structure of the model for the Winter Garden agroecosystem that is included due to the presence of $B t$ cotton. The difference between conventional cotton and $B t$ cotton is included in the insect larval stage in which, for $B t$ cotton, exposed and resistant (or toxicant-tolerant) components exist.

numerical procedures by using our own code and found that STELLA performed adequately for purposes of analyzing our model. We executed sensitivity studies by changing one parameter at a time to determine which parameters in the model impacted the food chain ecology as measured by growth of the population through reproduction, survivorship, and emigration. Table 1 indicates the 14 (16) parameters sensitive to ecological processes and valuation out of the 43 (45) parameters and initial conditions used in the conventional $(B t)$ cotton model. Baseline simulation parameters for the model were set at the midpoints of their estimated ranges. The daggers in Table 1 indicate parameters added in the modified model for bollworm larvae feeding on $B t$ cotton. Baseline and ranges for these 16 parameters were used in the model to generate simulations of characteristics of the bollworm and $B t$ cotton in the Winter Garden area of south-central Texas.

A suite of 5000 simulations was performed with parameters chosen at random from the distributional ranges of possible values associated with the sensitive parameters. Statistics such as the mean and significance of the results were computed from the simulations. Four model scenarios (numerical experiments) for both conventional and $B t$ cotton crops were created to 
TABle 1. Sensitive model parameters.

\begin{tabular}{|c|c|c|}
\hline Parameter & Baseline value & Range used in random simulations \\
\hline Natural survival of eggs $\left([6 \mathrm{~d}]^{-1}\right)$ & 0.15 & $0.1-0.2$ \\
\hline Egg pest mortality $\left(\mathrm{d}^{-1}\right)$ & 0.9 & $0.85-0.95$ \\
\hline Egg after-spray mortality $\left(\mathrm{d}^{-1}\right)$ & 0.05 & $0.0-0.1$ \\
\hline Natural survival of larvae $\left([18 \mathrm{~d}]^{-1}\right)$ & 0.75 & $0.6-0.8$ \\
\hline Larvae pest mortality $\left(\mathrm{d}^{-1}\right)$ & 0.9 & $0.85-0.95$ \\
\hline Larvae after-spray mortality $\left(\mathrm{d}^{-1}\right)$ & 0.05 & $0.0-0.2$ \\
\hline Natural survival of pupae $\left([17 \mathrm{~d}]^{-1}\right)$ & 0.95 & $0.9-1.0$ \\
\hline Natural survival of adults $\left([10 \mathrm{~d}]^{-1}\right)$ & 0.95 & $0.9-1.0$ \\
\hline No. eggs per capita (adult female) & 800 & $600-1000$ \\
\hline Proportion of moths migrating out of cotton plots $\left(\mathrm{d}^{-1}\right)$ & 0.45 & $0.25-0.65$ \\
\hline Boll damage rate $\left(\mathrm{d}^{-1}\right)$ & 0.3 & $0.2-0.4$ \\
\hline Early loss rate (bolls) $\left(\mathrm{d}^{-1}\right)$ & 0.002 & $0.001-0.003$ \\
\hline Non-insect loss rate (bolls) $\left(\mathrm{d}^{-1}\right)$ & 0.0015 & $0.001-0.002$ \\
\hline Insect immigration (no.) & 20000 & $17500-22500$ \\
\hline Proportion of resistant larvae $\dagger$ & 0.1 & $0.05-0.15$ \\
\hline No. days of exposuret & 5 & 3-8 \\
\hline
\end{tabular}

Notes: Sensitivity studies indicated that these parameters were the most important of the 45 parameters and initial conditions influencing dynamics and structuring the agroecosystem community. These parameters were used to determine the sensitivity of the model to perturbation through study of stochastic difference equation models.

$\uparrow$ Parameters added in the modified model for bollworm larvae feeding on Bt cotton.

address top insectivore removal and agricultural management schemes. The presence or absence of bats along with the utilization or non-utilization of insecticide sprays in the agroecosystem defined these scenarios. These scenarios allow comparison of different environments, different pest management strategies, and the role of bats in the agroecosystem.

\section{Comparison of the Winter Garden region and North Carolina}

To determine the consistency of the computed results for the Winter Garden region with existing data from North Carolina, several assumptions about the form of the data are needed. These include the following: (1) the model output measure of harvested cotton was seed cotton; (2) the model spray scenario was the same as Jackson et al.'s (2003) label of "pyrethroid-treated"; (3) the measure of $B t$ expression was Bollgard I, which contains the Cry1AC toxin; and (4) Jackson et al.'s (2003) conclusions were obtained for an environment with far less mammalian insectivory impact and thus is probably comparable to the "no bats" scenario in the model.

The information available from Texas and through Jackson et al. (2003) is at different levels of resolution. The Texas field data employed in the model are at the level of "parameter" and "process." From the model, we draw conclusions about the ecosystem level. The North Carolina data are presented at the agroecosystem level, which allows the comparison with the conclusions drawn from the model. Although North Carolina cotton is not the emphasis of our model studies, the Jackson et al. (2003) paper provided an indication that the Texas model was producing consistent information at the agroecosystem level. Another advantage from the modeling perspective is that North Carolina cotton data were sets of data independent from our focus area in Texas.

\section{RESULTS}

In this section, the results of the analysis of the simulation model are presented. We emphasize two ecological and three agronomic responses for the Winter Garden region. Our model results associated with these responses for Winter Garden, Texas, are compared with the field parameters obtained in a North Carolina cotton study.

\section{Model analysis}

The four model scenarios that address top insectivore removal and agricultural management schemes were utilized to study each of the conventional and the $B t$ cotton crops. Two ecological responses for the pest insects were investigated. The first was the average number and variation of adult bollworm moths surviving to emigrate from the crops. This response represents transport to other crops or natural regions in the agroecosystem or emigration to other crops north of the Winter Garden region. The second response was the number of non-harvestable bolls destroyed by larval damage, which is a measure of the impact of herbivory by the agricultural pests. This damage was tracked on the lower, middle, and upper two-thirds of the plant.

The indicators of agronomic response were the number of insecticide applications, the timings of the spray application schedule, and the cotton yield in numbers of harvested bolls per hectare. Table 2 presents the resultant summary statistics per scenario for the simulations performed with randomly chosen parameters in reasonable ranges on each of the model versions (conventional and $B t$ cotton crops).

\section{Ecological functions}

Conclusions drawn from our model simulations indicate that the planting of $B t$ cotton in the presence of a large population of insectivorous bats can have a 
TABLE 2. The growing-season means $( \pm \mathrm{SE})$ of results of model simulations for the scenarios involving three categories defined by (1) farmer's use of pesticidal sprays and not spraying, (2) presence of bats and their absence, and (3) plantings of conventional and $B t$ cotton.

\begin{tabular}{|c|c|c|c|c|c|c|}
\hline \multirow[b]{2}{*}{ Scenario } & \multicolumn{3}{|c|}{ No. bolls damaged/ha } & \multirow{2}{*}{$\begin{array}{c}\text { Total no. } \\
\text { bolls damaged/ha }\end{array}$} & \multirow{2}{*}{$\begin{array}{c}\text { No. spray } \\
\text { applications }\end{array}$} & \multirow{2}{*}{$\begin{array}{c}\text { Total no. insects } \\
\text { emigrating }\end{array}$} \\
\hline & Lower third & Middle third & Upper third & & & \\
\hline \multicolumn{7}{|l|}{ Conventional } \\
\hline \multicolumn{7}{|l|}{ Spray } \\
\hline No bats & $31753 \pm 98.0$ & $35049 \pm 172.1$ & $32511 \pm 263.2$ & $99313 \pm 85.4$ & $3.8 \pm 0.01$ & $23087 \pm 167.5$ \\
\hline Bats & $23733 \pm 44.4$ & $17444 \pm 76.5$ & $15539 \pm 109.8$ & $56717 \pm 116.2$ & $3 \pm 0.001$ & $74 \pm 14.5$ \\
\hline $\begin{array}{l}\text { Cost difference } \\
\text { (US\$/ha) }\end{array}$ & 11.5 & 25.1 & 24.2 & 60.9 & $\sim 25$ & \\
\hline \multicolumn{7}{|l|}{ No spray } \\
\hline No bats & $159723 \pm 194.6$ & $367775 \pm 34.2$ & $524537 \pm 378.3$ & $1052036 \pm 502.1$ & $\cdots$ & $236409 \pm 212.0$ \\
\hline Bats & $84797 \pm 89.2$ & $194613 \pm 804.7$ & $242734 \pm 270.6$ & $522143 \pm 930.1$ & $\ldots$ & $43071 \pm 63.6$ \\
\hline $\begin{array}{l}\text { Cost difference } \\
\text { (US\$/ha) }\end{array}$ & 107.0 & 247.4 & 402.6 & 757.0 & $\cdots$ & $\cdots$ \\
\hline \multicolumn{7}{|l|}{ Bt cotton } \\
\hline \multicolumn{7}{|l|}{ Spray } \\
\hline No bats & $28087 \pm 38.4$ & $31483 \pm 74.0$ & $15977 \pm 64.8$ & $75546 \pm 123.8$ & $3 \pm 0.003$ & $20612 \pm 10.6$ \\
\hline Bats & $24382 \pm 41.9$ & $34029 \pm 124.7$ & $19844 \pm 127.8$ & $78255 \pm 247.1$ & $1.2 \pm 0.008$ & $99 \pm 2.7$ \\
\hline $\begin{array}{l}\text { Cost difference } \\
\text { (US\$/ha) }\end{array}$ & 5.3 & -3.6 & -5.5 & -3.9 & $\sim 50$ & $\cdots$ \\
\hline \multicolumn{7}{|l|}{ No spray } \\
\hline No bats & $59699 \pm 80.8$ & $125547 \pm 186.9$ & $98989 \pm 182.2$ & $284237 \pm 394.9$ & $\cdots$ & $41275 \pm 34.8$ \\
\hline Bats & $30913 \pm 37.2$ & $59160 \pm 76.8$ & $44628 \pm 122.6$ & $134701 \pm 190.3$ & $\cdots$ & $351 \pm 4.9$ \\
\hline $\begin{array}{l}\text { Cost difference } \\
\text { (US\$/ha) }\end{array}$ & 41.1 & 94.8 & 77.7 & 213.6 & $\cdots$ & $\cdots$ \\
\hline
\end{tabular}

Notes: In a scenario, the agricultural response variables measure impact on cotton through the location and total numbers of damaged bolls plus the number of sprays required. The ecological response variable is the numbers of insects that emigrate over the growing season. Results were derived from 5000 random simulations of the model indicated in Appendix B. Mean differences between "No-bats" vs. "Bats" scenarios and "Conventional" vs. "Bt" cotton under the same scenario are all statistically significant $(P<0.05)$. The cotton plant population was structured by boll location in the lower, middle, or upper third of the plant. Cost differences are based on an assumption of 770 bolls $/ \mathrm{kg}$, US\$1.10/ $\mathrm{kg}$ cotton lint, and US\$25 per spray application. The italicized entries indicate the agronomics associated with a scenario and the ecological responses for the scenarios.

dramatic direct impact on the population dynamics of pest insects over a single growing season at least on a regional and perhaps even on a transcontinental scale. This is demonstrated by the prediction that when bats are not present the number of insects emigrating from $B t$ cotton is decreased considerably over the numbers of insects emigrating from non-transgenic cotton (Table 2). This conclusion is based on the assumptions that there are high densities of insectivorous bats, that the simulated time frame is a single growing season, and that a single generation of bollworms is produced on the cotton crop in the growing season. Each of these assumptions is valid for the Winter Garden region. Because the actual numbers of bats foraging in the Winter Garden region are unknown, we tested the robustness of our model relative to numbers of bats present by varying the percentage of the total energy demands of bats. A change in this percentage can be interpreted as either a perturbation in total bat numbers or as a modification of the energy demands of individual bats. A comparison between $B t$ and non-transgenic cotton for the number of damaged bolls as a function of the percentage of change was made with the baseline parameters used in the simulations. The number of damaged bolls fluctuates according to the timing and numbers of the insecticidal sprays. But, as Table 2 indicates, boll loss can be greater for $B t$ cotton than conventional cotton, especially when the expected number of bats is large. When the number of bats is small, conventional cotton has the greater number of damaged bolls. An ecological indicator, the number of bollworm emigrants, is a decreasing function of increasing bat numbers for both $B t$ and non-transgenic conditions.

The conclusions (Table 2) from our model analysis indicate that the number of bolls produced per hectare in the absence of Brazilian free-tailed bats results in crop yields for the conventional cotton genotypes and spray schedules that are strikingly consistent with the field estimates found in Jackson et al. (2003) (see Table 3 for a comparison). Indeed, Jackson et al. (2003) provide the only data set of which we are aware that contains sufficient information to provide a relatively complete comparison of the model output and data. The correspondence of model output and field data at the crop and pest levels provides a level of consistency from which to view effects of bat predation on insects in the agroecosystem. 
TABLE 3. A comparison of the field experimental results of Jackson et al. (2003: Tables 2, 4, and 5) with model results (Table 2).

\begin{tabular}{|c|c|c|c|c|c|c|c|c|}
\hline \multirow[b]{3}{*}{ Scenario/study } & \multicolumn{4}{|c|}{ Untreated } & \multicolumn{4}{|c|}{ Treated } \\
\hline & \multicolumn{2}{|c|}{ Conventional cotton } & \multicolumn{2}{|c|}{ Bt cotton } & \multicolumn{2}{|c|}{ Conventional cotton } & \multicolumn{2}{|c|}{ Bt cotton } \\
\hline & $\begin{array}{l}\text { Bolls damaged } \\
\text { ( } \% \text { of total) }\end{array}$ & $\begin{array}{c}\text { Yield } \\
(\mathrm{kg} / \mathrm{ha})\end{array}$ & $\begin{array}{l}\text { Bolls damaged } \\
\text { ( } \% \text { of total })\end{array}$ & $\begin{array}{c}\text { Yield } \\
(\mathrm{kg} / \mathrm{ha})\end{array}$ & $\begin{array}{l}\text { Bolls damaged } \\
\text { ( } \% \text { of total })\end{array}$ & $\begin{array}{c}\text { Yield } \\
(\mathrm{kg} / \mathrm{ha})\end{array}$ & $\begin{array}{l}\text { Bolls damaged } \\
\text { ( } \% \text { of total) }\end{array}$ & $\begin{array}{c}\text { Yield } \\
\text { (kg/ha) }\end{array}$ \\
\hline Jackson et al. (2003) & 46.2 & 1466.2 & 9.3 & 2870.5 & 17.6 & 2471.8 & 2.9 & 3016.4 \\
\hline Model results & 48.1 & 1474.6 & 13 & 2471.8 & 4.5 & 2711.9 & 3.5 & 2472.8 \\
\hline
\end{tabular}

Note: $B t$ cotton is a plant-incorporated protectant (PIP) cotton strain that expresses the genes of the soil bacterium Bacillus thuringiensis, in this case the cultivar BollGard (Monsanto, St. Louis, Missouri, USA).

\section{Agronomics}

The agronomic corollaries of our simulations show that on average, with spraying in non-transgenic conventional cotton, Brazilian free-tailed bats save producers US\$86/ha or US\$688000 in the 8000-ha region (derived from Table 2 by summing the costs of sprays saved and the damage to bolls). There is a $43 \%$ reduction in damage of cotton bolls attributed to the bat consumption of bollworms. In the null spray scenario, on average, the presence of bats reduces insect damage to cotton by $50 \%$ and thus saves US $\$ 683 /$ ha, although the net damage to cotton is substantially greater than when sprays are applied. In this scenario, savings in spray costs are lower than the losses in yield. Thus, as has been demonstrated for many years by the cotton producers, spraying is an economically viable option for non-transgenic cotton crops. The simulation scenario using non-transgenic cotton crops and with bats absent requires four sprays, whereas with bats present, the schedule was reduced to three sprays.

For $B t$ cotton, predation on moths by the bat population can reduce the number of sprays to two. In spite of a relatively small increase in boll damage caused by reduction in number of sprays and the change in the application times of the spray schedule, the impact of bats remains profitable for the cotton producer with a total savings of approximately US\$46/ha. An approximate $3.5 \%$ increase in the number of bolls damaged by insects when bats are absent reflects the fact that larval infestations require longer periods to reach the threshold levels that trigger insecticide applications (the accepted threshold is $20000 /$ ha). This generates a difference in loss of approximately US\$4/ha in the $B t$ crop. The model suggests that the $B t$ crop spray schedule is reduced from three to one insecticide spray per season because the presence of the bats keeps the number of larvae below the accepted threshold to apply an insecticide. If $B t$ cotton is not sprayed, the presence of foraging bats saves cotton producers an average of US\$214/ha.

The schedules for insecticide spraying where Brazilian free-tailed bats are present are consistent with current practices in the Winter Garden area where nontransgenic cotton crops are traditionally sprayed three to four times and $B t$ cotton usually requires at most one insecticide application. From a profit perspective, given the presence of bats in the Winter Garden region, a single spray saves the producer of $B t$ cotton US\$55/ha. Assuming that the cost of seed is the same, the number of insecticide applications are identical, all bolls are of a fixed (average) size, and bats are present, the economics of planting non-transgenic vs. Bt cotton favors $B t$ cotton by approximately US\$19/ha. When bats are not present, planting $B t$ cotton yields an increase in profit of approximately US\$59/ha over non-transgenic cotton, but there is significantly more damage to the crop as indicated by boll damage.

Our analyses demonstrate that, on average, agronomic contributions of Brazilian free-tailed bats are important to farmers. Even when insect numbers are reduced from systemic $B t$ toxins and by application of spray insecticides, bats still can have an impact on profitability of the crop. We demonstrated, from the results for number of bolls produced per hectare, that yields for $B t$ cotton and the insecticide treatments are similar in both Texas (see model results in Table 2) and North Carolina (see field estimates in Table 3).

\section{Discussion}

Highlights of this section include the following. First, the major theme focuses on the ecological and economic benefits provided by a large population of insectivorous bats and, to a lesser extent, the risks associated with loss of bats due to planting of $B t$ crops. A second theme is that the effects of $B t$ and frequently required insecticidal spray applications are important for agro-ecology. Consequences of the approximate six months that the bats spend in Mexico could be fundamental to the binational agro-ecosystem and its ecology, but we are unable to model this part of our system. The derivatives of $B t$ effects projected to longer time scales are important but at present we are unable to extend our simulation model nor can we appropriately discuss longer term evolutionary effects of Bt. Finally, a comparison of the agricultural environments of Winter Garden and North Carolina is given.

For longer time scales than the single growing season considered here, it is expected that a larger number of effects of $B t$ crops might be observed. These include the effects of $B t$ cotton in the model on bat populations and the feedback effects of bats on the dynamics of the entire system. The toxic effects of $B t$ could lead to adult 
bollworm densities that are insufficient to attract large numbers of bats. Because the bats are highly mobile polyphagous predators, they have the ability to find and use alternative resources (Lee and McCracken 2005). If the planting of $B t$ crops causes the bats to disperse to more insect-productive foraging areas, the local impact of the bats would be diminished from both the agronomic and ecological perspectives.

For approximately one-half of the year, the bat habitat is in Mexico. A major difficulty with expanding the time horizon from a single growing season is that detailed information about the crops, insects, and bats in Mexico is not available. The time frame of this study does not provide for serious consideration of the impact of $B t$ resistance in insects on the population dynamics of bats. With insectivorous bats present in their current high densities, the results suggest that the numbers of resistant insects emigrating per hectare would be relatively small (Table 2) when compared to the numbers of insects that could be produced in conventional cotton (for example, see Table 2, no-spray treatment and presence of bats). In addition, $B t$-resistant insects that survived the stress of the $B t$ toxins may be unfavorably influenced by $B t$ toxins (Tabashnik and Carrière 2004), with stressed insects being more susceptible to predation. Perhaps due to the presence of large numbers of Brazilian free-tailed bats, mobilization and development of a significant Bt-resistant bollworm population has not yet occurred. A delayed development of resistance would help alleviate the increased economic and ecological costs associated with the use of higher active ingredient spray rates of older insecticides and the deployment of new ones. Thus, the consumption of Btresistant bollworms by bats could have important longterm economic benefits for cotton producers both in the Winter Garden region and throughout the continental distributional range of $H$. zea.

Consumption by Brazilian free-tailed bats, as well as other insectivorous insects, birds, and mammals, reduces the numbers of insects in $B t$ cotton throughout the growing season. The expected reduction in bollworm populations from predation by bats and birds and their relationship to agricultural economics is both intriguing and incongruous, because under current agricultural control practices bollworms and other pest insects can, but only occasionally do, cause large economic losses in the Winter Garden region. We have suggested that to a considerable extent, this could be due to the presence and ecological control function of the substantial numbers of Brazilian free-tailed bats. However, if no bats were present, the model indicates that two additional sprays would be required, fewer bolls would be damaged, and more cotton bollworm moths would live to disperse throughout and beyond the Winter Garden cotton-growing region. This is because the efficacy of spray insecticide application is generally lower than the systemic $B t$ toxins. A regional effect can be expected with each successive bollworm generation.
These subsequent generations immigrate to other areas and can eventually consume plants other than cotton (Casimero et al. 2000). Direct effects can be expected as summarized in Table 2, where on average, the presence of Brazilian free-tailed bats reduces the need for one spray in conventional cotton and for two sprays in $B t$ cotton. Insecticide applications are effective in reducing eggs and larvae of pest insects, but have important social costs, such as health and environmental risks that are not included in the estimates given here. In our model computations, we included cost of insecticide applications but do not include the variable cost of the $B t$ seed and registration as well as the regulated requirement for refugia so that the costs presented are relative to the locality and can vary depending upon changing economic factors.

Although the ecological indicators suggest there are indirect effects of $B t$ on the translocation of bats, this has not been a focus of the present analysis. Should bat populations continue to decline in the Winter Garden area, possibly due to a transition of crops to PIP crops, their availability for suppressing insect pest populations would diminish commensurately.

While our model conclusions obtained with parameters chosen from the Winter Garden Area in southcentral Texas compared favorably with Jackson et al.'s (2003) data from North Carolina, neither Jackson et al.'s (2003) numbers nor ours correspond to similar results from the mid-southern states such as Arkansas (Bryant et al. 2003) and the Texas High Plains (Armstrong et al. 2003). The field data of which we are aware for the latter growing areas are not sufficiently detailed for parameter estimation in our model or to confirm the relationship between model output and data. However, important differences between these regions must occur as the production per hectare in the High Plains of Texas and in Arkansas is approximately one-half that of North Carolina.

The specific reasons for the similarity in the model for the Winter Garden Texas region and the cotton data from North Carolina are uncertain. However, the model parameters for each of the Winter Garden and the North Carolina agricultural regions must be similar because the Winter Garden model output is so close to the field data from North Carolina. Of course, it could be that the model has omitted important factors but we have attempted to minimize these errors of omission and feel that the model representations are basic to the issues discussed here. There are differences between the cotton crops in North Carolina and Texas, including planting times, precipitation, and soil types. North Carolina is near the northern limit for cultivation of cotton, with the plants primarily grown across the Coastal Plains and the Piedmont regions. These are regions with sandy loam soils, abundant flat land, and long growing seasons. They lie east of the Appalachian Mountains, where the average annual rainfall ranges mostly between 1016 and $1270 \mathrm{~mm}$. In most years precipitation is sufficient for 
crop growth, but much of the area is irrigated. Planting begins in mid-April and usually is finished by the end of May, depending upon the year. Strong insect pressure occurs in July when bollworm flights peak. Cotton farms in North Carolina are generally smaller than those of the Texas Winter Garden region. The Winter Garden region plants cotton early due to the subtropical climate and the consequent insect problems. Average rainfall is between 635 and $762 \mathrm{~mm} / \mathrm{yr}$ and a significant portion of the crop, up to $95 \%$, is irrigated. Planting usually begins in February and March in the Lower Rio Grande Valley. The soils are classified as heavy alluvial and desert. Massive emergences of bollworm moths occur in late June and early July from corn, which then move to cotton. The timing of growing-season events in North Carolina is delayed $\sim 30-45 \mathrm{~d}$ from those of the Texas growing season. Relative to this delay, bollworm infestations tend to peak slightly earlier in North Carolina than in Texas; rainfall probably is not an important factor because of irrigation availability; and alluvial and sandy loam soil types are each well suited to grow cotton.

On the scale of a farm crop in the Winter Garden, the conservation and ecological sustainability of bats appear to be crucial for farm management and pest control solutions. Pest management can have a significant impact on the local scale but it also helps reduce the impact of $H$. zea on regional and continental scales throughout the corn and cotton belts in the United States. There remain important unanswered questions about resistance, natural and mandated refuges, and agro-ecosystem sustainability. Notwithstanding, our conclusions corroborate the reduction of insecticide use for control of bollworm with $B t$ implementation, an important agronomic and environmental finding.

Global trade issues are forcing changes to U.S. federal government support programs for farmers. In the absence of financial support based on yields, producers may be likely to make agronomic decisions specifically based on profit. The ecosystem services provided by bats and other beneficial organisms represent avoided costs that can raise the profit margin of crop production on both local and regional scales. Failure to protect and conserve bat populations could have a significant local effect that would ultimately affect crop protection efforts along the migration pathway of bats from Mexico to the United States.

\section{ACKNOWLEDGMENTS}

This work was supported in part by cooperative agreement CR 83214801 with the U.S. Environmental Protection Agency (T. G. Hallam [PI], G. M. McCracken, S. T. Purucker, and T. H. Kunz [Co-PIs]), a grant from NSF (ITR 0326483; T. H. Kunz [PI], G. M. McCracken, M. Betke, J. Westbrook, Patricia Morton [Co-PIs]), by the Bat Working Group (T. H. Kunz, G. M. McCracken, and C. Cleveland [Co-PIs]) supported by the National Center for Ecological Analysis and Synthesis (a Center funded by a grant from NSF (DEB-0072909) to the University of California, Santa Barbara campus), by CONACYT grant G37425-V, CONACYT-SEMARNAT grant 2002-C01-0357, and additional support from the Program for Conservation of Mexican Bats, the U.S. Fish and Wildlife Service, National Fish and Wildlife Foundation, and the David and Lucille Packard Foundation. Bat Conservation International, Texas Parks and Wildlife Department, J. D. Bamburger, and Universidad Technical Monterrey supported earlier workshops on the economic value of bats. Rodney Sams, Seth Walker, Noel Troxclair, Ray King, Reagan King, Jim Parker, Kenneth White, Bain Walker, and Pat Morton provided valuable logistical support for our Texas field work. This paper has been reviewed in accordance with the U.S. Environmental Protection Agency's peer and administrative review policies and approved for publication.

\section{Literature Cited}

Adamczyk, J. J., Jr., and J. Gore. 2004. Development of bollworms, Helicoverpa zea, on two commercial Bollgard cultivars that differ in overall Cry1 Ac levels. Journal of Insect Science 4:32-37.

Adamczyk, J. J., Jr., and D. V. Sumerford. 2001. Potential factors impacting season-long expression of CrylAc in 13 commercial varieties of Bollgard cotton. Journal of Insect Science 1:13-19.

Armstrong, J. S., R. K. Boman, P. N. Johnson, and J. Blackshear. 2003. Economic evaluation of short season Bollgard cotton cultivars on the Texas high plains. Texas Journal of Agriculture and Natural Resources 16:78-85.

Broderick, N. A., K. F. Raffa, and J. Handelsman. 2006. Midgut bacteria required for Bacillus thuringiensis insecticidal activity. Proceedings of the National Academy of Sciences (USA) 103:15196-15199.

Bryant, K. J., R. L. Nichols, C. T. Allen, N. R. Benson, F. M. Bourland, L. D. Earnest, M. S. Kharboutli, K. L. Smith, and E. P. Webster. 2003. Transgenic cotton cultivars: an economic comparison in Arkansas. Journal of Cotton Science 7:194-204.

Burd, T., J. R. Bradley, Jr., and J. W. Van Duyn. 1999. Performance of selected Bt cotton genotypes against bollworm in North Carolina. Pages 931-934 in P. Dugger and D. Richter, editors. Beltwide Cotton Conference Proceedings. National Cotton Council, Memphis, Tennessee, USA.

Casimero, V., R. Tsukuda, F. Nakasuji, and K. Fujisaki. 2000. Effect of larval diets on the survival and development of larvae in the cotton bollworm, Helicoverpa armigera Hübner (Lepidoptera: Noctuidae). Applied Entomology and Zoology 35:69-74.

Cleveland, C. J., et al. 2006. Estimation of the economic value of the pest control service provided by the Brazilian freetailed bat in south-central Texas. Frontiers in Ecology and the Environment 5:238-243.

Davis, R. B., C. F. Herreid II, and H. L. Short. 1962. Mexican free-tailed bats in Texas. Ecological Monographs 32:311-346.

Groot, A. T., and M. Dicke. 2002. Insect-resistant transgenic plants in a multi-trophic context. Plant Journal 31:387-406.

Hilbeck, A., M. Baumgartner, P. M. Fried, and F. Bigler. 1998. Effects of transgenic Bacillus thuringeinsis corn-fed prey on mortality and development time of immature Chrysoperia carnea (Neuroptera: Chrysopidae). Environmental Entomology $27: 480-487$.

IRAC [Insecticide Resistance Action Committee]. 2005. Mode of action classification. Poster Version 1. CropLife International, Washington, D.C., USA.

Jackson, R. E., J. R. Bradley, Jr., and J. W. Van Duyn. 2003. Field performance of transgenic cottons expressing one or two Bacillus thuringiensis endotoxins against bollworm, Helicoverpa zea (Boddie). Journal of Cotton Science 7:57-64.

James, C. 2006. Global status of commercialized Biotech/GM crops: 2005. Brief Number 34. International Service for the Acquisition of Agri-biotech Applications, Ithaca, New York, USA. 
Johnson, D. R., G. M. Lorenz, J. D. Hopkins, and L. M. Page. 2002. Control of the Heliotine complex in bollgard cotton cultivars, 1998-1999. Pages 245-247 in Proceedings of the 2000 Cotton Research Meeting. Arkansas Agricultural Experiment Station, Fayetteville, Arkansas, USA.

Keeley, A. T. H., and B. W. Keeley. 2004. The mating system of Tadarida brasiliensis (Chiroptera: Molossidae) in a large highway bridge colony. Journal of Mammalogy 85:113-119.

Kunz, T. H., J. O. Whitaker, Jr., and M. D. Wadanoli. 1995. Dietary energetics of the Mexican free-tailed bat (Tadarida brasiliensis) during pregnancy and lactation. Oecologia 101: 107-115.

Lee, Y.-F., and G. F. McCracken. 2002. Foraging activity and resource use of Brazilian free-tailed bats, Tadarida brasiliensis (Molossidae). Ecoscience 9:306-313.

Lee, Y.-F., and G. F. McCracken. 2005. Dietary variation of Brazilian free-tailed bats links to migratory populations of pest insects. Journal of Mammalogy 86:67-76.

McCracken, G. F. 2003. Estimates of population sizes in summer colonies of Brazilian free-tailed bats (Tadarida brasiliensis). Pages 21-30 in T. J. O'Shea and M. A. Bogan, editors. Monitoring trends in bat populations of the United States and territories: problems and prospects. Information and Technology Report USGS/BRD/ITR-2003-003. U.S. Geological Service, Springfield, Virginia, USA.

Marvier, M., C. McCreedy, J. Regetz, and P. Kareiva. 2007. A meta-analysis of effects of $B t$ cotton and maize on nontarget invertebrates. Science 316:1475-1477.

Mols, C. M. M., A. J. van Noordwijk, and M. E. Visser. 2005. Assessing the reduction of caterpillar numbers by Great Tits Parus major breeding in apple orchards. ARDEA 93:259269.
Romeis, K., M. Meisssle, and F. Bigler. 2006. Transgenic crops expressing Bacillus thuringiensis toxins and biological control. Nature Biotechnology 24:63-71.

Sansone, C., T. Isakeit, R. Lemon, and B. Warrick. 2002. Texas cotton production. Emphasizing integrated pest management. Publication B-6116. Texas Cooperative Extension, Texas A\&M University, College Station, Texas, USA.

Sansone, C. G., and J. W. Smith. 2001. Natural mortality of Helicoverpa zea (Lepidoptera: Noctuidae) in short season cotton. Biological Control 30:113-122.

Tabashnik, B. E., and Y. Carrière. 2004. Bt transgenic crops do not have favorable effects on resistant insects. Journal of Insect Science 4:1-3.

van Lenteren, J. C. 1993. Biological control in protected crops: where do we go? Pesticide Science 36:321-327.

Westbrook, J. K., R. S. Eyster, W. W. Wolf, P. D. Lingren, and J. R. Raulston. 1995. Migration pathways of corn earworm (Lepidoptera: Noctuidae) indicated by tetroon trajectories. Agricultural and Forest Meteorology 73:67-87.

Whitaker, J. O., Jr., C. Neefus, and T. H. Kunz. 1996. Dietary variation in the Mexican free-tailed bat (Tadarida brasiliensis). Journal of Mammalogy 77:716-724.

Williams, M. R. 2006. Cotton insect losses-2005. In Proceedings of Beltwide Cotton Production and Research Conference. CD-ROM. National Cotton Council, Memphis, Tennessee, USA.

Wolf, W. W., J. K. Westbrook, J. R. Raulston, S. D. Pair, and P. D. Lingren. 1995. Radar observations of orientation of noctuids migrating from corn fields in the Lower Rio Grande Valley. Southwestern Entomologist 18(Supplement):45-61.

\section{APPENDIX A}

Model equations indicating the nature of the dynamical system used to investigate the interactions between insects and cotton (Ecological Archives A018-027-A1).

\section{APPENDIX B}

Rationale and discussion for model parameters (with references) (Ecological Archives A018-027-A2). 